\title{
Gastrointestinal Endoscopic Terminology Coding (GET-C): A WHO-Approved Extension of the ICD-10
}

\author{
Marcel J. M. Groenen • Willem Hirs • Henk Becker • \\ Ernst J. Kuipers • Gerard P. Van Berge Henegouwen • \\ Paul Fockens • Rob J. Th. Ouwendijk
}

Received: 19 January 2006 / Accepted: 16 February 2006 / Published online: 16 February 2007

(C) Springer Science+Business Media, Inc. 2007

\begin{abstract}
Technological developments have greatly promoted interest in the use of computer systems for recording findings and images at endoscopy and creating databases. The aim of this study was to develop a comprehensive WHO-approved code system for gastrointestinal endoscopic terminology. The International Classification of Diseases, 10th edition (ICD-10), and the ICD-10 clinical modification (ICD-10-CM) were expanded to allow description of every possible gastrointestinal endoscopic term under conditions defined by the WHO. Classifications of specific gastroin-
\end{abstract}

M. J. M. Groenen $(\bowtie) \cdot$ E. J. Kuipers

Department of Gastroenterology and Hepatology, Erasmus

Medical Center,

Dr. Molewaterplein 40,

3015 GD Rotterdam, The Netherlands

e-mail:mgroenen@knmg.nl

W. Hirs

WHO-FIC Collaborating Centre in the Netherlands, RIVM/cVTV, Bilthoven, The Netherlands

\section{H. Becker}

Department of Family Practice, Academic Medical Center, Amsterdam, The Netherlands

G. P. Van Berge Henegouwen

Department of Gastroenterology, University Medical Center Utrecht,

Utrecht, The Netherlands

P. Fockens

Department of Gastroenterology, Academic Medical Center, Amsterdam, The Netherlands

\section{R. J. T. Ouwendijk}

Department of Internal Medicine and Gastroenterology, Ikazia hospital,

Rotterdam, The Netherlands testinal disorders and endoscopic locations were added. A new chapter was developed for frequently used terminology that could not be classified in the existing ICD-10, such as descriptions of therapeutic procedures. The new extended code system was named Gastrointestinal Endoscopic Terminology Coding (GET-C). The GET-C is a complete ICD10-related code system that can be used within every endoscopic database program for all specific endoscopic terms. The GET-C is available for free at http://www.trans-it.org/.

Keywords Gastrointestinal endoscopy · International classification of diseases $\cdot 10$ th Edition (ICD-10) $\cdot$ ICD-10 clinical modification $\cdot$ Coding $\cdot$ Terminology $\cdot$ Database

\section{Introduction}

Technological developments and the introduction of hospital information systems have greatly promoted interest in the use of computer systems for recording findings and images at endoscopy. Several database systems have been developed for this purpose, most working only as a report generator. These systems are, however, hampered by the lack of a specific code system for endoscopic diagnoses and terminology. As a result of this shortcoming, the composition of reports and storage of data differ considerably between systems. Systems use different database structures and variable terminology and are thus not compatible or comparable.

The International Classification of Diseases (ICD) is designed to promote international comparability in the collection, processing, classification, and presentation of mortality statistics. This ICD is developed, published, and maintained by the World Health Organization (WHO). The system is, in its current setting, not applicable for endoscopy, as it does not include descriptive terminology. However, endoscopic 
findings are classified according to their appearance. Adequate description of this appearance in uniform terminology is essential for the interpretation of endoscopy reports and allows important conclusions to be made with respect to therapy and prognosis. Thus it is important to uniformly store and code endoscopic findings. This is, however, hampered by the lack of a specific, uniformly applicable code system for endoscopic terminology and findings. In addition, only about $80 \%$ of report systems are able to use a code in their database [1].

Different coding systems for medical data are being used. The ICD, 9th edition (ICD-9), and the clinical modification of the ICD-9 (ICD-9-CM) have already been used and proven to be of value in a specific and defined gastrointestinal endoscopic setting [2]. The ICD has been revised periodically to incorporate changes in the medical field. The tenth edition (ICD-10) differs from the ninth edition in several ways, although the overall content is similar. First, the ICD-10 has alphanumeric categories rather than numeric categories. Second, some chapters have been rearranged, some titles changed, and conditions have been regrouped. Third, the ICD-10 has almost twice as many categories as the ICD-9. The ICD-10 has been available since 1992 and was translated into Dutch in 1997 [3]. Other medical specialities, such as oncology and dentistry, have produced an extended code system for their field of interest based on the ICD-10 [4].

The aim of this project is to develop a comprehensive code system for gastrointestinal endoscopic terminology, based on the widely accepted ICD-10 code system, that can be used in any gastrointestinal endoscopic information system.

\section{Methods}

As a basis for the new coding system the latest edition of the ICD, the ICD-10, was chosen. The reason for choosing this code system was that a predecessor has already been in use for some gastrointestinal endoscopic databases [2]. In addition, the current version of the ICD is now accepted in a majority of countries throughout the world [5].

Extensions of the ICD-10 are made according to the recommendations of the $\mathrm{WHO}$, without changing the structure of the ICD-10. The first four characters are never changed, but one or more characters are added behind these first four descriptors. In this way it is always possible to delete the extension to come back to the original ICD-10. We used the Dutch translation of the ICD-10. Also, the draft version of the ICD-10-CM of the National Center for Health Statistics (NCHS) was studied, which is available on the Internet [6]. Conflicts with this ICD-10 CM system were avoided, to rule out coding conflicts.
A working group, the TRANS.IT working group, was founded, comprised of representatives from two academic hospitals (Utrecht, Amsterdam) and four general hospitals. This working group used the Endobase III system (Olympus). In this system, the endoscopist can choose among three methods of writing reports. Besides the Minimal Standard Terminology (MST) [7], text-blocks and standard reports are also available. A standard report is a complete report based on a diagnosis or a combination of diagnoses. With text-blocks, different portions of the text are combined to compose a complete report. These two variants enable more rapid generation of reports and are well accepted and widely used in the Netherlands [8].

In the TRANS.IT project group, which was founded as a peer reference group, standard reports, text-blocks, and linkage to the new code system were discussed.

A list of every endoscopic finding, intervention, or complication described using one of the three methods of report writing available for TRANS.IT users was generated. All items on this list were linked to a specific code.

\section{Results}

We first generated a list of the different fields necessary for evaluation of endoscopic data (Table 1). The program automatically generated the data during the composition of endoscopic reports. All these fields are necessary to generate a comprehensive anonymous database with endoscopic information for extensive research. In addition, demographic data such as gender and age of patients and specialty of referring doctor are recorded.

We included all available standard reports, text-blocks, and diagnoses of Minimal Standard Terminology (MST) accepted by the TRANS.IT group. The endoscopic findings, interventions, and complications were extracted and linked to a specific code. In this way, a total of 316 standard reports and 1571 text-blocks were coded, to assure coding of every item within this project.

Table 1 Different fields that need a specific code in endoscopic information systems

Reason for endoscopy
Medication use
Sedation and medication during endoscopy
Preparation
Procedure for investigation
Endoscopic diagnosis/findings
Therapeutic and diagnostic interventions
Histology results
Therapy started
Advice to referring doctor
Complications


In total, 2593 different items were extracted and received a specific code. Of these items, 630 (24\%) could be coded with the existing ICD-10. Thus, 1963 new codes were required and added to the ICD-10 system, in order to be able to specifically code every endoscopic term.

The ICD-10 used was originally designed for mortality and discharge statistics. The problem with that design is that the structure used in the ICD-10 is not very detailed. This is true especially for gastrointestinal endoscopic terms, which do not always include a mortality risk but, most of the time, descriptive items essential for prognosis and therapy. For example, specific descriptions of peptic ulcers are relevant for determination of outcome risks, therapy, and prognosis. We therefore introduced the Forrest classification for description of gastric and duodenal ulcers [9]. We thus, for instance, changed the diagnosis K25.2 (acute gastric ulcer with both hemorrhage and perforation) to K25.21 (acute gastric ulcer with spurting bleeding and perforation; Forrest Ia) in the Gastrointestinal Endoscopic Terminology Coding (GET-C; Table 2).

Besides such an adaptation of the ICD-10 system, endoscopy is still developing and new terms and endoscopic techniques are continuously being created. For example, new disease classifications are being introduced from time to time, such as the semirecent Los Angeles classification for reflux esophagitis $[9,10]$.

For several fields, there was no ICD-10 code available, and the item thus could not be categorized under an existing ICD-10 code. For example, the procedure for investigation and interventions could not be covered within the ICD-10 or even the ICD-10-CM system. Because these items are essential for good analysis of endoscopic data, a new chapter with the same structure as the ICD-10 was developed. The items in this new chapter start with the letters OG. We chose to categorize therapeutic interventions in this new chapter also because new therapies are developed frequently and can now be adapted.

Adaptations were made in different chapters of the ICD10. In Chapter 1, Certain Infectious and Parasitic Diseases (A00-B99), the exact locations in the gastrointestinal tract of some specific infections were added. In Chapter 2, Neoplasms (C00-D48), besides the exact locations in the gastrointestinal tract, the endoscopic characteristics of polyps were described and coded in more detail. It is important to register whether a polyp is pedunculated, sessile, or flat or has a villous endoscopic aspect. Also, the number of polyps found in a specific part of the intestine must be coded, because of important diagnostic and therapeutic options for patients and the follow-up of these patients.

In Chapter 9, Diseases of the Circulatory System (I00I99), hemorrhoids and varices were described according to a classification. Different gradings of protrusion were used for hemorrhoids. Paquet's endoscopic classification for esophageal varices was coded [11].

Most changes were, however, made in Chapter 11, Diseases of the Digestive System (K00-K93). The description of esophagitis was divided into different origins and severity. Gastric and duodenal ulcers were coded according to the Forrest classification and their specific location in the stomach or duodenum. Gastritis and duodenitis were coded according to their specific location and the endoscopically suspected cause. Inflammatory bowel diseases were coded according to their endoscopic severity and location. Some complications related to gastrointestinal procedures were coded in more detail.

In Chapter 18 symptoms, signs, and abnormal clinical and laboratory findings that are an indication for endoscopic investigations were coded in more detail. In Chapter 21 postoperative situations important for gastrointestinal endoscopic investigations such as gastric and colon operations were extensively coded.

In the new, thirteenth chapter of the GET-C, about 446 new codes were generated. These codes start with the letters OG. The first part of this chapter includes coding of various indications for endoscopy that could not be categorized in the ICD-10. The second part consists of specific codes for detailed locations in the gastrointestinal tract. The third part includes procedures, which are divided into diagnostic and therapeutic procedures. Diagnostic procedures include, for example, sampling of histology and culture specimens. Examples of therapeutic procedures are different kinds of polypectomies, endoscopic mucosal resections, placement of endoprotheses, and dilatation of stenoses. Another aspect of these therapeutic interventions was used for the management of gastrointestinal bleeding such as injection therapy with or without coagulation, band ligations, and clipping. Preparation and procedure for the endoscopic examination are also coded in this chapter.

The extensions of the GET-C were checked by the Dutch translation board of the ICD-10 to preclude any conflicts between the two code systems.

\section{Discussion}

The increased use of computer systems in health care and the need for communication between these systems necessitate the availability of generally accepted code systems. Good coding provides epidemiological information for research purposes. Coding is of importance for hospitals and professionals because most of the financial systems used in health care are based on different codes. In addition, good coding makes statistical analysis of different diagnoses and collection of rare diagnoses easier. With an internationally accepted code, it is possible to compare and share 
Table 2 Comparison of ICD-10 and GET-C codes for gastric ulcer

\begin{tabular}{|c|c|c|c|}
\hline ICD-10 & Description & GET-C & Description \\
\hline \multirow[t]{3}{*}{ K25.0 } & \multirow[t]{3}{*}{ Gastric ulcer, acute with hemorrhage } & $\mathrm{K} 25.0$ & Gastric ulcer, acute with hemorrhage \\
\hline & & $\mathrm{K} 25.01$ & Gastric ulcer, acute with spurting bleeding (Forrest Ia) \\
\hline & & $\mathrm{K} 25.02$ & Gastric ulcer, acute with nonspurting active bleeding (Forrest Ib) \\
\hline $\mathrm{K} 25.1$ & Gastric ulcer, acute with perforation & $\mathrm{K} 25.1$ & Gastric ulcer, acute with perforation \\
\hline \multirow[t]{3}{*}{$\mathrm{K} 25.2$} & \multirow[t]{3}{*}{$\begin{array}{l}\text { Gastric ulcer, acute with both hemorrhage and } \\
\text { perforation }\end{array}$} & $\mathrm{K} 25.2$ & Gastric ulcer, acute with both hemorrhage and perforation \\
\hline & & K25.21 & $\begin{array}{l}\text { Gastric ulcer, acute with spurting bleeding and perforation } \\
\text { (Forrest Ia) }\end{array}$ \\
\hline & & K25.22 & $\begin{array}{l}\text { Gastric ulcer, acute with nonspurting active bleeding and } \\
\text { perforation (Forrest Ib) }\end{array}$ \\
\hline \multirow[t]{5}{*}{ K25.3 } & \multirow[t]{5}{*}{$\begin{array}{l}\text { Gastric ulcer, acute without hemorrhage or } \\
\text { perforation }\end{array}$} & K25.3 & Gastric ulcer, acute without hemorrhage or perforation \\
\hline & & $\mathrm{K} 25.31$ & Gastric ulcer, acute with visible vessel (Forrest IIa) \\
\hline & & K25.32 & Gastric ulcer, acute nonbleeding with overlying clot (Forrest IIb) \\
\hline & & $\mathrm{K} 25.33$ & Gastric ulcer, acute with hematin-covered basis (Forrest IIc) \\
\hline & & K25.34 & Gastric ulcer, acute with clean ulcer ground (Forrest III) \\
\hline K25.5 & $\begin{array}{l}\text { Gastric ulcer, chronic or unspecified with } \\
\text { perforation }\end{array}$ & K25.5 & Gastric ulcer, chronic or unspecified with perforation \\
\hline \multirow[t]{3}{*}{$\mathrm{K} 25.6$} & \multirow[t]{3}{*}{$\begin{array}{l}\text { Gastric ulcer, chronic or unspecified with both } \\
\text { hemorrhage and perforation }\end{array}$} & K25.6 & $\begin{array}{l}\text { Gastric ulcer, chronic or unspecified with both hemorrhage and } \\
\text { perforation }\end{array}$ \\
\hline & & K25.61 & $\begin{array}{l}\text { Gastric ulcer, chronic or unspecified with spurting bleeding and } \\
\text { perforation (Forrest Ia) }\end{array}$ \\
\hline & & K25.62 & $\begin{array}{l}\text { Gastric ulcer, chronic or unspecified with non- spurting active } \\
\text { bleeding and perforation (Forrest Ib) }\end{array}$ \\
\hline \multirow[t]{5}{*}{ K 25.7} & \multirow[t]{5}{*}{$\begin{array}{l}\text { Gastric ulcer, chronic without hemorrhage or } \\
\text { perforation }\end{array}$} & K25.7 & Gastric ulcer, chronic without hemorrhage or perforation \\
\hline & & $\mathrm{K} 25.71$ & Gastric ulcer, chronic with visible vessel (Forrest IIa) \\
\hline & & K25.72 & $\begin{array}{l}\text { Gastric ulcer, chronic non-bleeding with overlying clot (Forrest } \\
\mathrm{IIb} \text { ) }\end{array}$ \\
\hline & & $\mathrm{K} 25.73$ & Gastric ulcer, chronic with hematin-covered basis (Forrest IIc) \\
\hline & & $\mathrm{K} 25.74$ & Gastric ulcer, chronic with clean ulcer ground (Forrest III) \\
\hline \multirow[t]{5}{*}{ K25.9 } & \multirow[t]{5}{*}{$\begin{array}{l}\text { Gastric ulcer, unspecified, without hemorrhage or } \\
\text { perforation }\end{array}$} & K25.9 & Gastric ulcer, unspecified, without hemorrhage or perforation \\
\hline & & K25.91 & Gastric ulcer, unspecified, with visible vessel (Forrest IIa) \\
\hline & & K25.92 & $\begin{array}{l}\text { Gastric ulcer, unspecified, nonbleeding with overlying clot } \\
\text { (Forrest IIb) }\end{array}$ \\
\hline & & K25.93 & $\begin{array}{l}\text { Gastric ulcer, unspecified, with hematin-covered basis (Forrest } \\
\text { IIc) }\end{array}$ \\
\hline & & K25.94 & Gastric ulcer, unspecified, with clean ulcer ground (Forrest III) \\
\hline
\end{tabular}

information in one field of interest. Most currently used coding systems are regional or national. Only some coding systems, such as the ICD-10, are translated into different languages and used in different countries.

For endoscopic report writing and endoscopic databases, different systems have been developed. These systems are now being used at many hospitals. We used the Endobase III system from Olympus Europe in our project to compose reports and record different codes. The system runs as a network version with different workstations as well as a stand-alone unit.

The Endobase III system enables the generation of reports via three pathways; in addition to standard reports and text- blocks, the latest translated version of the MST is also used to compose an endoscopic report. Thus it is essential that all differently generated data are coded in the same way to enable analysis of the data anonymously. In this system, all standard reports and text-blocks are linked to one or more specific GET-C codes. The choice of a standard report or text-block leads directly to the recording of the correct GET$\mathrm{C}$ code in the Endobase III database. Due to the structure of the MST, the automatic link for it is more complex to realize. We chose to link the diagnoses with the GET-C code, which is separately selected within the MST by the endoscopist at the end of the report. Automatic linking is essential to 
ensure correct and complete selection of codes and to make the system workable for endoscopists.

In the TRANS.IT project, an anonymous central database of endoscopic investigations was built. In this central database, only coded data instead of free text can be collected, for privacy reasons. After 3 years of use, a database of about 120,000 investigations using the same coding system has been built by this working group. The GET-C system allows the encoding of any data collected during endoscopic investigations and recorded in any endoscopic database. By extending the ICD-10 with respect to the structure developed by the WHO, it is always possible to extract the original ICD-10 code from the GET-C. Thus, it is possible to link the endoscopic database with other health-care systems throughout the world.

Because endoscopy is an evolving medical specialty, new techniques are continuously becoming available. These require new codes, which will be discussed within the TRANS.IT project.

The Dutch Association of Gastroenterologists has accepted the GET-C. The GET-C will be available for use in other systems and was discussed at the WHO Family of International Classifications Network meeting in October 2004 [12]. The GET-C is available for free at http://www.transit.org. We hope that this coding system will help to make endoscopic databases and endoscopic report writing programs more meaningful.

\section{References}

1. Teuffel W, Stettin J (2001) Electronic documentation in endoscopy: present status and future perspectives from a company standpoint. Endoscopy 33:276-279

2. Cooper GS, Chak A, Lloyd LE, Yurchick PJ, Harper DL, Rosenthal GE (2000) The accuracy of diagnosis and procedural codes for patients with upper GI hemorrhage. Gastrointest Endosc 51:423426

3. WHO, NRV-WCC (1997) Internationale Statistische Classificatie van Ziekten en met Gezondheid verband houdende Problemen Tiende Revisie. CSIZ

4. http://www.who.int/whosis/icd10/special.htm

5. http://www.who.int/whosis/icd10/implemen.htm

6. http://www.cdc.gov/nchs/about/otheract/icd9/abticd10.htm

7. Delvaux M, Crespi M, Armengol-Miro JR, Hagenmuller F, Teuffel W, Spencer KB, Stettin J, Zwiebel FM (2000) Minimal standard terminology for digestive endoscopy: results of prospective testing and validation in the GASTER project. Endoscopy 32:345-355

8. Groenen MJM, Kuipers EJ, van Berge Henegouwen GP, Fockens P, Ouwendijk RJTh (2006) Computerisation of endoscopy reports using standard reports and text blocks. Neth J Med 64:25-30

9. Forrest JA, Finlayson ND, Shearman DJ (1974) Endoscopy in gastrointestinal bleeding. Lancet 2:394-397

10. Lundell LR, Dent J, Bennett JR, Blum AL, Armstrong D, Galmiche JP, Johnson F, Hongo M, Richter JE, Spechler SJ, Tytgat GN, Wallin L (1999) Endoscopic assessment of oesophagitis: clinical and functional correlates and further validation of the Los Angeles classification. Gut 45:172-180

11. Paquet KJ (1976) [Diagnostic and therapeutic measures in acute catastrophic bleeding esophageal varices]. Fortschr Med 94:19411946

12. WHO Family of International Classifications Network Meeting (2004) http://www.nordclass.uu.se/WHOFIC/reykjavik. htm\#Report 